\title{
COMUNICAÇÃO ENQUANTO ESTRATÉGIA DE FORMAÇÃO E FORTALECIMENTO DA IDENTIDADE DE ELITES NO MARANHÃO
}

\author{
Ingrid Pereira de Assis ${ }^{1}$
}

\begin{abstract}
Resumo: Este artigo apresenta parte das apreensões de uma pesquisa desenvolvida durante o mestrado em Ciências Sociais, na Universidade Federal do Maranhão (UFMA). Seu foco é no uso dos meios de comunicação como estratégia de fortalecimento de uma identidade para ascensão e a reconversão da notoriedade obtida, por meia dela, em poder nos espaços: econômico, político e intelectual. Utilizou-se como procedimentos metodológicos entrevistas em profundidade, para reconstrução das trajetórias dos agentes pesquisados, e análise de discurso a partir de coleta realizada em um blog pertencente à um membro de uma família, para perceber as estratégias de reprodução acionadas por um caso exemplar de família de origem libanesa que migrou para o Estado do Maranhão. Exemplar, pois, as apreensões extraídas desta análise podem ser aplicadas a outros casos semelhantes no Estado.
\end{abstract}

Palavras-chave: Poder. Estratégia. Imigração. Comunicação.

\section{COMMUNICATION AS A STRATEGY FOR TRAINING AND STRENGTHENING THE IDENTITY OF ELITES IN MARANHÃO}

Astract: This article presents part of the apprehensions of a research developed during the master's degree in Social Sciences, at the Federal University of Maranhão (UFMA). Its focus is on the use of the media as a strategy to strengthen an identity for ascension and the reconversion of the notoriety obtained by half of it in power in the economic, political and intellectual spaces. Methodological procedures were used as in-depth interviews, to reconstruct the trajectories of the researched agents, and discourse analysis based on the collection carried out in a blog belonging to a member of a family, in order to understand the reproduction strategies triggered by an exemplary case of family of Lebanese origin that migrated to the State of Maranhão. Exemplary, therefore, the apprehensions extracted from this analysis can be applied to other similar cases in the State.

Keywords: Power. Strategy. Word. Immigration. Communication.

\footnotetext{
${ }^{1}$ Bolsista Capes. Doutoranda do Programa de Pós-Graduação em Jornalismo, da Universidade Federal de Santa Catarina (UFSC), em Florianópolis, Brasil; mestre em Ciências Sociais, pela Universidade Federal do Maranhão (UFMA), São Luís, Maranhão; e bacharel em Comunicação Social - Hab. Jornalismo, também pela UFMA. E-mail: ingrid.po.assis@hotmail.com.
} 


\section{Introdução}

Falar de imigrantes no Brasil, especificamente libaneses, é ter em mente todo um processo de deslocamento e, posterior, assimilação de estratégias de reprodução que acarretam em uma reconversão e consagração esses agentes. E, embora esta consagração esteja relacionada aos espaços econômico, político e intelectual, não se pode deixar de perceber a interferência no espaço midiático. Esta pesquisa faz parte de outra mais ampla, desenvolvida no mestrado em Ciências Sociais da Universidade Federal do Maranhão, cujo objetivo foi analisar como alguns membros de famílias de descendentes de libaneses no Maranhão conseguem converter a ascensão econômica em afirmação política. No entanto, a opção por recortar, especificamente, o espaço midiático se deu, primeiramente, para aproximar e tentar trabalhar de forma interdisciplinar duas áreas: a Comunicação Social (Jornalismo) e as Ciências Sociais; e, por fim, para estimular discussões relacionadas à mídia, identidade e poder.

$\mathrm{Na}$ pesquisa ${ }^{2}$, que deu base para este artigo, foi realizada a análise da trajetória dos agentes, para entender quais estratégias de reprodução, reconversão e consagração estes descendentes de imigrantes libaneses, excepcionalmente bem-sucedidos, utilizam para alcançar posições de destaque nos espaços econômico, político, intelectual e midiático. Primeiramente, fez-se a coleta das possibilidades de objetos que serviriam para esta análise. As famílias de imigrantes libaneses no Maranhão são muitas, por isso, partiu-se para a delimitação do número de agentes a serem estudados, usando como critério o fato de que deveriam ser famílias com membros que ocupam ou ocuparam alguma posição política no Estado (neste caso, foram representantes das famílias que aqui serão nomeadas como X, Y e Z ${ }^{3}$ ).

\footnotetext{
2 Esta pesquisa original fez parte dos trabalhos desenvolvidos no Laboratório de Estudos sobre Elites Políticas e Culturais (LEEPOC), que é vinculado ao Departamento de Sociologia e Antropologia e ao Programa de Pós-graduação em Ciências Sociais da Universidade Federal do Maranhão (UFMA), e cujos professores responsáveis são Eliana Tavares dos Reis e Igor Gastal Grill.

${ }^{3}$ Letras usadas para preservar a identidade dos membros das famílias analisadas.
} 
Para este artigo, será usado um dos casos exemplares analisados, que é o da família X. Este acaba sendo muito relevante por estar presente nos mais diversos espaços: econômico, político, intelectual e midiático. Trata-se de um caso exemplar por sustentar a construção de um imaginário coletivo de sucesso. Este arquétipo permite observar o movimento de ascensão social e afirmação econômica no Maranhão, tendo a família iniciado com o destaque econômico obtido por meio do comércio, e feito posterior direcionamento dos benefícios obtidos no espaço econômico para o mundo político, por João $X^{4}$, que começou sua carreira política em 1945, e o filho dele José $X^{5}$, já na década de 1980. Além, claro, do destaque no mundo intelectual e midiático, que marca a trajetória de José $\mathrm{X}$. Vale ressaltar que o exame dos itinerários destes agentes permitiu perceber que as estratégias para a mobilidade ascensional e transformação em "elite" independem do momento histórico vivenciado, estando, ao que parece, mais atreladas às propriedades do espaço político.

Como base para tal análise, foi utilizada a pesquisa desenvolvida pelo professor do Programa de Pós-Graduação em Ciências Sociais da Universidade Federal do Maranhão (UFMA), Igor Gastal Grill, publicada no livro "Amazônia: desenvolvimento, meio ambiente e diversidade sociocultural" (2009). Intitulado "Descendentes de Imigrantes na política do Rio Grande do Sul e do Maranhão: ascensão social, afirmação eleitoral e cooptação política", o artigo, que traz os resultados da pesquisa, mostra que, tanto o "processo de entrada na política desses agentes (descendentes de imigrantes), como as tentativas mais ou menos eficazes de reprodução dos seus 'grupos familiares' em posições eletivas só é possível mediante o exame das cadeias de rivalidades e alianças que estabeleceram com outros agentes pertencentes a camadas sociais mais 'antigas' e mais 'recentes' na política” (2009, p. 137).

No artigo de Grill (2009), nomes de representantes políticos descendentes

\footnotetext{
${ }^{4}$ Nome fictício.

${ }^{5}$ Nome fictício também.
} 


\section{Universidade do Extremo Sul Catarinense \\ Revista lbero-Americana de Humanidades, Ciências e \\ Educação \\ UnesC Produção e democratização do conhecimento na lbero-América}

de imigrantes, aparecem em um quadro sinóptico, no qual são descritas as bases sociais dos agentes e os cargos políticos que ocuparam. Tratam-se de "perfis representativos" que permitem observar uma "mobilidade circular", controlada por segmentos mais tradicionais "via processos de cooptação"6. O autor analisa, comparativamente, as cadeias de rivalidades e alianças de políticos descendentes de imigrantes do Rio Grande do Sul e do Maranhão. Grill examina as estratégias de transmissão do patrimônio familiar, os investimentos em patrimônio escolar e econômico e o acúmulo de capital social pelos agentes estudados. Com a comparação entre as trajetórias dos agentes de dois Estados diferentes, ele consegue identificar semelhanças, como as três formas de afirmação no espaço social (de agentes provenientes de famílias já estabelecidas; de agentes de famílias que ascenderam na primeira metade do século XX, descendentes de imigrante; e agentes oriundos das camadas mais baixas, economicamente, da sociedade) e a tendência à profissionalização política a partir do ingresso precoce na carreira, ou seja, entre 18 e 30 anos (GRILL, 2009).

É possível perceber, então, que mesmo tão diferentes social, política e economicamente, o Maranhão e o Rio Grande do Sul apresentam semelhanças com relação às diferentes formas de afirmação social de agentes que adentram o espaço político. Mobilizando um esquema analítico semelhante, esta pesquisa foca na relação do espaço midiático neste processo de mobilidade ascensional de alguns descendentes de imigrantes libaneses no Maranhão, sobretudo, os que se destacaram no espaço político.

Também, serviram de base para esta pesquisa as reflexões de Pierre Bourdieu. Para este autor, os agentes podem mobilizar recursos multidimensionais e legitimar suas dominações em diferentes espaços. Para analisar como esses agentes ocupam dadas posições e se deslocam no espaço

6 Grill (2009, p. 226) usa a definição de cooptação de Garraud: "No domínio político, a cooptação constitui um modo de recrutamento particular resultando de uma seleção interna e prévia aos jogos e aos mecanismos eleitorais, os quais apenas ratificam e legitimam uma escolha anterior". Aqui, noção é empregada no mesmo sentido. 


\title{
Universidade do Extremo Sul Catarinense \\ Revista lbero-Americana de Humanidades, Ciências e \\ Educação \\ Unesc Produção e democratização do conhecimento na lbero-América
}

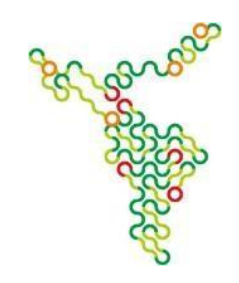

social, conseguindo estar em mais de uma posição de destaque, utilizou-se a análise de trajetórias sociais, proposta por Bourdieu (2002a, 2002b e 2004), partindo de procedimentos metodológicos como entrevistas em profundidade e análise documental.

Dessa forma, é por meio da reconstrução da trajetória desses agentes que se pretende compreender a formação deles como políticos no espaço familiar. Também por ela, é possível perceber quais estratégias são acionadas (consciente ou inconscientemente) por esses agentes e que acabam contribuindo, decisivamente, para a ocupação e destaque em certos ambientes sociais, como o espaço midiático. Pierre Bourdieu, notadamente, permite entender de quais modos a dominação pode ser ativada ao longo de diferentes gerações de uma família. Ele lista: estratégias matrimoniais, de sucessão, educativas, econômicas, de reconhecimento simbólico, de sociodicéias, dentre outras. Para o autor, nos momentos necessários e oportunos, os agentes ativam essas formas de perpetuar o poder, seja ele econômico, simbólico, intelectual ou político. Segundo Bourdieu:

\begin{abstract}
Las estrategias de reproducción constituyen un sistema y, con ese título, están al principio de suplencias funcionales y de efectos compensatorios ligados a la unidad de función; las estratégias matrimoniales pueden, por ejemplo, suplir al fracaso de las estrategias de fecundidad. Del hecho de que ellas se aplican en puntos diferentes del ciclo de vida como proceso irreversible, lãs diferentes estrategias de reproducción están también cronológicamente articuladas, cada una de ellas, debiendo en cada momento contar con los resultados esperados por aquella que le ha precedido o que tiene un alcance temporal más corto: es así, por ejemplo, que en la tradición béarnesa, las estrategias matrimoniales

dependen muy directamente de las estrategias de fecundidad de la familia, por intermedio del número y del sexo de los hijos, pretendientes potenciales a una "dote" o a una compensación; pero también de las estrategias educativas, en las que el éxito era la condición de la aplicación de estrategias buscando separar de la herencia a las hijas y a los hijos menores (unas a través del matrimonio apropiado y los otros a través del celibato o la emigración) y en fin, de las estrategias propiamente económicas buscando entre otras cosas el mantenimiento o el aumento del patrimônio (2002, p. 7).
\end{abstract}

O autor explica que as estratégias de reprodução constituem um sistema. Sendo assim, entre as diferentes estratégias pode haver um efeito 


\section{Universidade do Extremo Sul Catarinense \\ Revista lbero-Americana de Humanidades, Ciências e \\ Educação \\ UnesC Produção e democratização do conhecimento na lbero-América}

compensatório, para suprir o fracasso de uma estratégia aciona-se outra. Além disso, elas estão cronologicamente articuladas de forma que o resultado dessa articulação é a manutenção ou aumento do patrimônio. "Essas estratégias orientam-se seja para a conservação da estrutura seja para a sua transformação, e pode-se genericamente verificar que quanto mais as pessoas ocupam uma posição favorecida na estrutura, mais elas tendem a conservar ao mesmo tempo a estrutura e sua posição" (BOURDIEU, 2004, p. 29). Para compreender como cada estratégia é acionada pelos agentes e como isso permitiu que eles conseguissem chegar à determinada posição política, fez-se necessário reconstruir as trajetórias de algumas personagens envolvidas nesse processo de chegada ao Maranhão. Esta reconstrução faz-se importante para compreender, inclusive, o uso da comunicação neste processo.

Dessa forma, na pesquisa macro que deu origem a este artigo, são mostrados os casamentos realizados por alguns membros das famílias pesquisadas e explicado de que forma isso ajuda na manutenção e, por vezes, no aumento do capital econômico e social familiar. É explicitada, também, a mudança no modelo de formação escolar, que passa a valorizar paulatinamente o diploma, o que contribui para a legitimação familiar em um espaço social que está cada vez mais objetivado. "...os diplomas escolares são para o capital cultural o que a moeda é para o capital econômico. (...) O diploma escolar, à semelhança da moeda, tem um valor convencional, formal, juridicamente garantido, portanto, livre das limitações locais" (BOURDIEU, 2002, p. 198).

Este investimento no capital escolar e as alianças matrimoniais terão como consequência uma ampliação das relações sociais desses agentes, que vão influenciar, inclusive, no espaço midiático alcançado, como se poderá ver mais à frente. Recorrendo às formulações de Carl $\mathrm{H}$. Landé é possível trabalhar com a sua concepção de relação diádica, que para esta pesquisa é importante para entender as relações que viabilizam os cargos ocupados, como essas relações se dão, se são horizontais ou

verticais, como são construídas e de que forma são úteis para os agentes em questão. Segundo Carl 
H. Landé: "Uma relação diádica, no seu sentido de ciência social, é uma relação direta envolvendo alguma forma de interação entre dois indivíduos. A palavra chave nessa definição é direta. Implica ligação pessoal" (1977, p. 1). Vale destacar que "distingue uma relação diádica de uma relação na qual dois atores estão ligados um ao outro indiretamente como uma conseqüência do fato de ocuparem lugares ou posições que estão interligadas ou de serem membros de um mesmo grupo" (1977, p. 3). Lembrando que dois indivíduos podem estar ligados em relações diádicas e não-diádicas ao mesmo tempo.

À frente, serão mostradas as relações estabelecidas por João X e José X, que vão oportunizar a eles possibilidades econômicas, oportunidades políticas e midiáticas. Em alguns casos, essas relações diádicas possibilitam a eles ocupar cargos públicos, obter financiamento político, concessões públicas de rádios e TV's etc. "As relações sociais informais são responsáveis pelos processos metabólicos necessários para que se mantenha a instituição formal em operação" (WOLF, 2003, p. 94). A análise das alianças diádicas, dos matrimônios e dos investimentos educacionais e econômicos dos agentes analisados, permite compreender de que forma acontece essa transmissão da herança política, mecanismo que pouco está relacionado à ideia de vocação natural, tão defendida entre os agentes. Segundo Canêdo: “...a vocação exigida para a participação no campo político não tem nada de natural: o habitus do político depende de uma preparação especial. Algo como iniciação com provas e ritos de passagem para inculcar o domínio prático de toda a produção acumulada pelo trabalho político dos profissionais antigos" (1991, p. 222).

Neste processo de transmissão, a avaliação social de um membro, acaba recaindo sobre a família como um todo. Por isso, essas famílias ficam conhecidas na sociedade local e os feitos de um membro acabam sendo convertidos em notoriedade para todos do grupo. Como destacou Grill, em estudo sobre a construção de "heranças políticas", a edificação dos "nomes" que conferem valor simbólico aos "grupos" decorre da "possibilidade de maximizar o reconhecimento desfrutado pela 'família' e suas inscrições na memória local por meio da valorização do 'nome', da 'imagem', dos 'feitos' e, sobretudo, dos 'fundadores'e 


\title{
Universidade do Extremo Sul Catarinense \\ Revista lbero-Americana de Humanidades, Ciências e \\ Educação \\ Unesc Produção e democratização do conhecimento na lbero-América
}

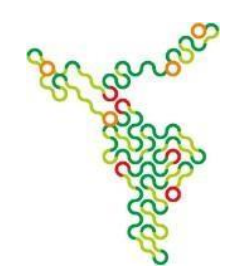

'sucessores' da 'tradição política familiar'” (2008b, p. 64). Ou seja, constituem "estratégias de reconversão do capital simbólico acionadas a partir do 'nome", mediante a seguinte combinação de lógicas:

...a apresentação da biografia coletiva, sobretudo no que se refere aos cargos e posições ditas públicas, e a reivindicação da posse pela 'família' de valores ou atributos morais. Ambas são inseparáveis nas estratégias das 'famílias' e nas narrativas. A conduta pública é a base da comprovação de valores morais, e a sedimentação desses valores é percebida como 'qualidades inatas' e pertencentes à 'família' (GRILL, 2008b, p. 68).

Nesta pesquisa, fez-se necessário, também, conhecer o patrimônio dos membros das famílias, bem como as profissões seguidas por seus integrantes, além das ações que enaltecem o valor simbólico familiar. Isto ajudará a entender porque essas famílias conseguiram certas alcunhas: "excelentes comerciantes", "famílias de políticos", "famílias muito ricas". Sendo isso vinculado ao fato de serem descendentes de libaneses.

\begin{abstract}
A filiação a uma família não define apenas a medida de crédito social de alguém. Ela também estrutura a natureza dos recursos sociais sob o comando dessa pessoa em operações envolvendo não-parentes. As relações de parentesco têm duas vantagens sobre as de nãoparentesco nesse tipo de manobra. Em primeiro lugar, elas são 0 produto da sincronização social realizada no curso da socialização. A relação privada de confiança pode assim ser traduzida, no domínio público, como cooperação (WOLF, 2003, p.101 e 102).
\end{abstract}

Em resumo, o autor explica que o pertencimento a uma dada família está relacionado aos recursos sociais que determinado agente pode acionar. Além disso, ele destaca que as relações de parentesco podem culminar em cooperação no espaço público. Como a própria generalização com relação aos integrantes da família X permite perceber, ser "um X" implica não apenas em carregar o sobrenome, mas todo o conceito de família economicamente bem sucedida o que, em alguns momentos, pode, até mesmo, abrir portas no espaço social.

Outro conceito trabalhado por Eric Wolf fundamental para essa pesquisa é o de amizade instrumental. Nesse tipo de relação, pesam o afeto entre os envolvidos, e, sobretudo, os benefícios que se pode obter por meio dela (WOLF, 


\section{Universidade do Extremo Sul Catarinense \\ Revista lbero-Americana de Humanidades, Ciências e \\ Educação \\ Unesc Produção e democratização do conhecimento na lbero-América}

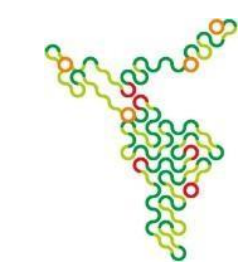

2003). Ao longo da trajetória dos representantes políticos das famílias selecionadas para esta pesquisa, será possível perceber que, em alguns momentos, essas amizades instrumentais possibilitarão para eles benefícios econômicos e políticos.

Vale ressaltar que certas alianças, como as amizades instrumentais, por vezes, são transmitidas, tal qual um patrimônio familiar, entre os herdeiros políticos. José X, por exemplo, relata as amizades "herdadas" do pai, como poderá ser observado mais à frente. Grill (2008b) destaca a esse respeito que há uma retroalimentação entre socialização e acessos derivados da familiaridade com o meio. Isto é, por um lado, a relevância "na diferenciação entre os pares" da "familiaridade com meio

político (...) rituais e linguagens", além "do contato com políticos na esfera doméstica". Por outro lado, tal "familiaridade" oportuniza "acessos (a postos, nominatas, cargos, órgãos, imprensa, etc.)" e "potencial de trânsito dos agentes no espaço social e político" (GRILL, 2008b, p. 64). Isso permite compreender que no momento de o agente ser selecionado para adentrar o espaço político e nas diferentes etapas da carreira, as alianças e amizades instrumentais são importantes. Sendo que muitas delas são decorrentes do pertencimento familiar. Todas essas articulações, acionamentos das amizades instrumentais, utilização de estratégias para a transmissão de poder político e econômico entre integrantes de famílias descendentes de libaneses são realizados em um contexto mais amplo, marcado, sobretudo, pela presença de uma forte estrutura que foi adjetivada de "oligárquica".

Sendo assim, no período no qual muitas dessas famílias vivenciam o crescimento econômico, a política do Maranhão é marcadamente controlada por alguns segmentos estabelecidos social e politicamente, ou seja, monopolizada por grupos políticos familiares e marcada pela dominação personalizada. Entre 


\title{
Universidade do Extremo Sul Catarinense \\ Revista lbero-Americana de Humanidades, Ciências e \\ Educação \\ Unesc Produção e democratização do conhecimento na lbero-América
}

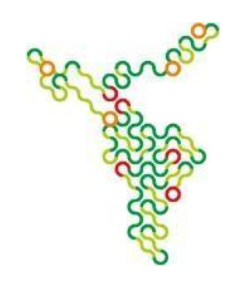

a entrada e saída de Victorino Freire ${ }^{7}$ de José Sarney ${ }^{8}$ e seus aliados, de Jackson $\operatorname{Lago}^{9}$ e o retorno de Roseana Sarney ${ }^{10}$, o pesquisador Flávio Reis defende que não há uma superação do sistema oligárquico, mas, sim, crises intra-oligárquicas e revezamento de grupos políticos ávidos pelo poder. Segundo o autor: "A crise na oligarquia liga-se fundamentalmente à crise do Estado, mas as respostas não têm se processado de maneira a incorporar e dinamizar novas formas institucionais, para além das antigas práticas oligárquicas de apropriação. Ao contrário, de certa maneira podemos perceber uma nova roupagem das velhas práticas de loteamento e composição parlamentar" (REIS, 2007, p.16).

E é neste contexto político que as famílias de descendência libanesa são cooptadas após o sucesso empresarial, conforme observa Grill (2008a): "No segundo estado (Maranhão), há igualmente a obtenção de notoriedade advinda do sucesso empresarial, porém essa proporciona a fixação na capital e a cooptação para o exercício de cargos políticos, para a direção das máquinas

\footnotetext{
7 Victorino Freire chegou ao Maranhão na década de 1930 e exerceu cargos políticos vinculados ao Maranhão por quase 30 anos. Tal período ficou conhecido como Vitorinista, que foi derrotado pelos Oposicionistas, grupo de José Sarney.
}

\begin{abstract}
8 José Sarney é membro da Academia Brasileira de Letras e foi o presidente do Brasil, entre os anos de 1985 a 1990. Foi governador do Estado do Maranhão de 1966 a 1971. Foi eleito presidente do senado nos anos de 1995, 2003, 2009 e 2011. A eleição de Sarney para governador do Maranhão, no ano de 1965, foi apontada como responsável pelo fim da oligarquia Vitorinista no Maranhão.
\end{abstract}

9 Jackson Kléper Lago, filiado ao Partido Democrático Trabalhista (PDT), foi governador do Maranhão, de 2007 a 2009, quando teve seu mandato cassado pelo Tribunal Superior Eleitoral (TSE), passando a assumir o cargo Roseana Sarney, que havia sido derrotada. Foi prefeito de São Luís de 1989 a 1992, de 1997 a 2000 e de 2001 a 2002.

${ }^{10}$ Roseana Sarney é filha do ex-presidente da República, José Sarney, e irmã do deputado federal, Sarney Filho, e do empresário, Fernando Sarney. No ano de 1990, candidatou-se à deputada federal pelo Partido da Frente Liberal (PFL) e foi eleita. Foi eleita governadora do Maranhão em 1994 e 1998. Em 2006, foi candidata pela terceira vez ao governo do Maranhão, mas perdeu para Jackson Lago. Em abril de 2009, o Tribunal Superior Eleitoral (TSE) cassou o mandato de Jackson Lago por abuso de poder econômico e político nas eleições de 2006. , foi candidata pela terceira vez ao governo do Maranhão, mas perdeu para Jackson Lago. Em abril de 2009, o Tribunal Superior Eleitoral (TSE) cassou o mandato de Jackson Lago por abuso de poder econômico e político nas eleições de 2006. Com a cassação, foi ordenada a posse de Roseana Sarney como governadora do Maranhão. Em 2010, Roseana Sarney voltou a ser eleita para o cargo de governadora do Maranhão e, na eleição seguinte, foi substituída por Flávio Dino. 


\section{Universidade do Extremo Sul Catarinense \\ Revista lbero-Americana de Humanidades, Ciências e \\ Educação \\ UnesC Produção e democratização do conhecimento na lbero-América}

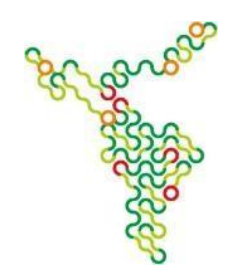

políticas estaduais e para as candidaturas" (2008a, p.17).

Com efeito, esses descendentes de imigrantes passam a fazer parte dos grupos políticos e, aos poucos, familiares, por meio da constituição de matrimônios com as famílias já estabelecidas no espaço político local. Paralelamente a esse movimento, entram em jogo as estratégias de dominação já mencionadas. É importante frisar que esses agentes ao adentrarem os espaços públicos e políticos, na maioria das vezes, o fazem já inicialmente em cargos de alto escalão ou em cargos eletivos centrais. Suas trajetórias nesses espaços já começam no topo. E são justamente essas posições ocupadas que servem de instrumento de cooptação para os grupos estabelecidos.

Outra questão importante de ser abordada é que tais agentes defendem uma relação com dada etnia e se reconhecem enquanto imigrantes ou descendentes. A migração é a inserção de um indivíduo em uma cultura diferente da sua, por isso, surgem questões relativas à adaptação e, no caso da imigração libanesa para o Maranhão, o destaque social, econômico e político obtido por alguns desses indivíduos, que acaba se tornando a identidade da etnia como um todo, em uma sociedade diferente da de origem. Dessa forma, paralelamente à discussão sobre as estratégias de afirmação social mobilizadas pelos agentes e a importância de suas relações diádicas (LANDÉ, 1977) para a obtenção de acessos, faz-se necessário refletir sobre a questão da identidade desses agentes enquanto pertencentes a um grupo específico, que, neste caso, trata-se da descendência libanesa, e a ideia difundida de serem bons comerciantes, políticos exímios e bons negociadores, enquanto uma identidade imprimida por eles mesmos em suas estratégias de auto consagração. Isto acaba por ser assimilado pela sociedade como algo inato da etnia. Tal concepção é fortalecida pelos agentes nos respectivos canais comunicativos dos quais detêm propriedade ou têm forte vínculo com os proprietários.

A identificação com a etnia libanesa é um aspecto relevante para esta pesquisa a partir do momento que serve de mecanismo de identificação e produção de um grupo que cria símbolos de solidariedade, reconhecimento e mobilização, tal como ocorre com os agentes estudados. Rogers 


\section{Universidade do Extremo Sul Catarinense \\ Revista lbero-Americana de Humanidades, Ciências e \\ Educação \\ UnesC Produção e democratização do conhecimento na lbero-América}

Brubaker e Frederick Cooper (2001) explicam que o conceito de identidade é usado de tantas formas diferentes, mas eles concebem identidade enquanto uma categoria analítica. A expressão identidade é utilizada por eles para dar sentido às suas atividades, ao que eles compartilham entre si e ao que os difere dos demais. Ao mesmo tempo, essa palavra ganha uma conotação política quando é utilizada para persuadir as pessoas a pensarem em seus interesses e organizá-los em prol de uma ação coletiva. Brubaker e Cooper (2001), entretanto, optam por utilizar o termo identificação no lugar da noção de identidade, que para eles estaria subsumida no clichê construtivista com múltiplas possibilidades interpretativas. Eles explicam, ainda, que a noção de identidade pode fundar-se em concepções fracas e fortes do termo, e, por isso, defendem a substituição pelo termo identificação, mais adequada quanto 0 objetivo é separar posturas essencialistas e abordagens mais construtivistas.

Nas trajetórias, é possível perceber esse trabalho de identificação com a etnia e de diferenciação perante a sociedade maranhense. Nota-se que esta identificação é compartilhada por um grupo solidário entre seus integrantes, com elos fortes e sentimento de pertencimento comum. É importante ter em mente, também, que a identificação de algumas dessas famílias com a etnia permite entender de que forma valores e características peculiares a alguns indivíduos passam a servir de caracterização para todo um grupo social e de que forma esses agentes trabalham para produzir símbolos de enaltecimento e reconhecimento familiar, por meio dessa aproximação com o que seria a "cultura libanesa". Este discurso de reconhecimento é, também, exaltado nos veículos de comunicação, o que ajuda no fortalecimento desta concepção no imaginário popular.

\section{Considerações sobre o estudo de caso dos X}

José $X$ foi secretário de Estado do Esporte e Lazer e se formou em Direito, na Universidade Federal do Maranhão (UFMA), no ano de 1985, mas não seguiu a carreira jurídica nem a acadêmica. José $X$ foi eleito para o parlamento estadual 


\section{Universidade do Extremo Sul Catarinense \\ Revista lbero-Americana de Humanidades, Ciências e \\ Educação \\ Unesc Produção e democratização do conhecimento na lbero-América}

pela primeira vez em 1982, quando foi o mais jovem parlamentar do Brasil. Em seguida, foi eleito deputado federal constituinte e, posteriormente, voltou a ser deputado estadual até o ano de 2011. Desde jovem, ele se aproximou da literatura. É membro da Academia Maranhense de Letras. Pela dedicação de José $X$ à atividade literária, é possível encontrar vários textos seus sobre a história de sua família, reproduzidos principalmente, em veículos de comunicação nos quais possui ações, ou cujos donos fazem parte do seu círculo de amizade e influência.

Para compreender sua relação com a mídia, vale pontuar que, entre os anos de 1987 e 1988, José X resolveu investir na área de radiodifusão, tornandose sócio da maior rede de comunicação do Estado do Maranhão, que pertence em parte à uma família política e cujo sócio foi amigo de colégio de José $X$. Percebe-se, então, claramente uma amizade instrumental. O irmão mais novo, Pedro $X^{10}$, também é empresário e, segundo Ana $X$ (mãe dos dois), atua administrando o patrimônio de José $X$. Como já dito, em uma família de políticos a profissão de todos acaba sendo usada em prol da afirmação política de alguns agentes. Estando o irmão disposto a usar seus conhecimentos administrativos para gerenciar as empresas de José $\mathrm{X}$, este obtém tempo livre para atuar enquanto homem político, fazendo visitas, participando de reuniões, confraternizando com coligados, e, também, enquanto intelectual, produzindo filmes, livros e textos no geral. Provavelmente, tais ações seriam impossibilitadas caso ele tivesse que se voltar para administração de suas empresas.

Por causa da relação econômica e pessoal com o maior sistema de comunicação do Estado e seu proprietário, é fácil compreender o convite para integrar a lista de blogueiros hospedados no portal da empresa, o segundo mais antigo do sistema. O blog existe desde outubro de 2006 é atualizado até hoje. A análise do uso deste espaço dentro deste veículo de comunicação demonstra o quanto são mobilizadas estratégias comunicativas que fortalecem a idealização da vocação comercial e do talento econômico que, aos poucos, são convertidos para outros espaços como o político e o intelectual, por exemplo.

De forma bastante resumida, pode-se pontuar que o espaço do blog é 


\section{Universidade do Extremo Sul Catarinense \\ Revista lbero-Americana de Humanidades, Ciências e \\ Educação \\ UnesC Produção e democratização do conhecimento na lbero-América}

usado por José X, inúmeras vezes, para ressaltar seus "feitos" dentro do espaço político. Um exemplo disso é o discurso de posse na Academia Maranhense de Letras, no dia 2 de outubro de 2009. Ele não apenas transcreve o seu discurso no blog, como também transcreve o discurso de outrem sobre o mesmo assunto. Também são transcritos outros discursos. Mesmo quando leva para o seu blog o discurso proferido por ele, José $X$ sempre se refere a si em terceira pessoa. Isso permite apreender que há uma preocupação em estabelecer certo distanciamento, ainda que se saiba que se trata de um texto com o interesse específico de enaltecimento pessoal. O mesmo pode ser visto nas postagens em que o político/intelectual/empresário fala a respeito da história familiar ou feitos políticos do pai. A narrativa é de celebração. No espaço do blog, também, são publicados relatos de outrem que versem sobre José $X$ ou sua família, normalmente enaltecendo as figuras públicas ou o valor histórico da família para o Maranhão.

Em postagens de cunho histórico, é comum o resgate à identificação com origem libanesa, atrelando-a, sempre, a aspectos positivos e fortalecendoo enquanto "naturais" da etnia. Na postagem "Vinte anos sem João X", por exemplo, publicada no dia 7 de setembro de 2013, ele escreve: "Para quem não sabe, João $X$ era filho de imigrantes libaneses e nasceu na cidade de Pindaré-Mirim em dezembro de 1933. Foi comerciante e político e em suas duas atividades sobressaiu-se por sua imensa criatividade e pela maneira sempre alegre e extrovertida de ser". Em uma simples frase, ele enaltece a figura do pai, ligando a ela características como se fossem inatas àquela figura. Joaquim liga a ideia de criatividade que teria colaborado para o sucesso do pai na política à informação de que ele era imigrante libanês. Estes são apenas alguns exemplos dentre os vários que podem ser observados lendo o blog do José $X$. Tais postagens, aliadas à análise da trajetória dos agentes da "família X", permitem compreender uso da mídia em favor da consolidação e transmissão familiar do poder político. Este uso aliado ao poder econômico e político fortalecem a imagem de tal família enquanto detentora de qualidades que justificam e sedimentam a sua posição enquanto elite, qualidades estas 
divulgadas enquanto "naturais" e não construídas a partir de um aprendizado muito próprio ainda no seio familiar.

\section{Referências}

BOURDIEU, Pierre. Os usos sociais das Ciências. São Paulo: Editora Unesp, 2004.

Estrategias de reproducción y modos de dominación.

Colección Pedagógica Universitária, enero-junio/julio-diciembre. 2002ª , p. 37-38.

- Os modos de dominação. In: BOURDIEU, P. A produção da crença: contribuição para uma economia dos bens simbólicos. São Paulo: Zouk, 2002b.

BRUBAKER, Rogers; COOPER, Frederick. Beyond identity. Theory and Society. 29, 2000.

CANEDO, Letícia Bicalho. Estratégias familiares na produção social de uma qualificação política. Educação \& Sociedade, nº 39, agosto/1991.

GRILL, Igor Gastal. Descendentes de imigrantes na política do Rio Grande do Sul e do Maranhão: ascensão social, afirmação eleitoral e cooptação política. In: FERRETTI, S.; RAMALHO, J.R. (Orgs.). Amazônia: desenvolvimento, meio ambiente e diversidade sociocultural. São Luís: Edufma, 2009.

- Processos, condicionantes e bases sociais da Especialização política no Rio Grande do Sul e no Maranhão. Revista Sociologia e Política, V.16, n 30, Curitiba, Junho 2008a.

$2008 b$.

Heranças políticas no Rio Grande do Sul. Edufma: São Luís,

GRILL, Igor Gastal; REIS, Eliana Tavares dos. O que escrever quer dizer na política? Gêneros de escrita e carreiras políticas. Trabalho apresentado na Anpocs, 2011.

LANDÉ, Carl H. A Base Diádica do Clientelismo. In: SCHIMIDT; S. W. [et al.] 
Universidade do Extremo Sul Catarinense

Revista lbero-Americana de Humanidades, Ciências e

Educação

Unesc Produção e democratização do conhecimento na lbero-América

(eds.). Tradução para fins didáticos de Friends, followers and factions.

Berkeley: University of Califórnia Press, 1977.

REIS, Flávio. "15 anos depois”. In: REIS, Flávio. Grupos Políticos e Estrutura

Oligárquica no Maranhão. São Luís: Unigraf, 2007.

WOLF, Eric. Antropologia e poder. Editora Universidade de Brasília: São Paulo, 2003. 